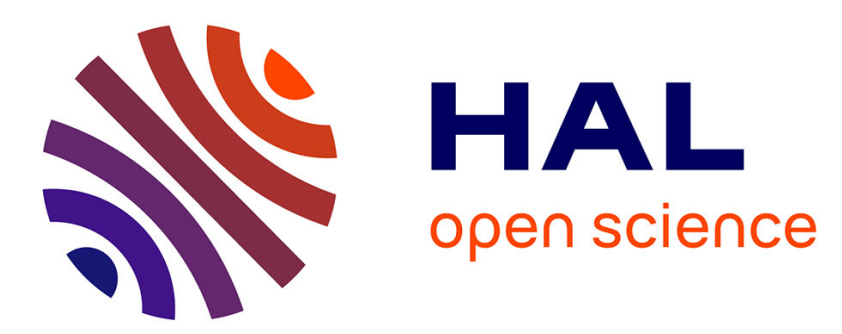

\title{
Formation of an inorganic-organic host-guest material by intercalation of acetone formaldehyde sulfite polycondensate into a hydrocalumite structure
}

\author{
Johann Plank, Friedrich von Hoessle
}

\section{- To cite this version:}

Johann Plank, Friedrich von Hoessle. Formation of an inorganic-organic host-guest material by intercalation of acetone formaldehyde sulfite polycondensate into a hydrocalumite structure. Journal of Inorganic and General Chemistry / Zeitschrift für anorganische und allgemeine Chemie, 2010, 636 (8), pp.1533. 10.1002/zaac.201000001 . hal-00552439

\section{HAL Id: hal-00552439 \\ https://hal.science/hal-00552439}

Submitted on 6 Jan 2011

HAL is a multi-disciplinary open access archive for the deposit and dissemination of scientific research documents, whether they are published or not. The documents may come from teaching and research institutions in France or abroad, or from public or private research centers.
L'archive ouverte pluridisciplinaire HAL, est destinée au dépôt et à la diffusion de documents scientifiques de niveau recherche, publiés ou non, émanant des établissements d'enseignement et de recherche français ou étrangers, des laboratoires publics ou privés. 


\section{Zeitschrift für Anorganische und}

Allgemeine Chemie

\section{Formation of an inorganic-organic host-guest material by intercalation of acetone formaldehyde sulfite polycondensate into a hydrocalumite structure}

\begin{tabular}{|r|l|}
\hline Journal: & Zeitschrift für Anorganische und Allgemeine Chemie \\
\hline Manuscript ID: & zaac.201000001.R1 \\
\hline $\begin{array}{r}\text { Wiley - Manuscript type: } \\
\text { Author: }\end{array}$ & Article \\
\hline Complete List of Authors: & $\begin{array}{l}\text { Plank, Johann; Technische Universität München, Institute of } \\
\text { Inorganic Chemistry } \\
\text { von Hoessle, Friedrich; Technische Universität München, Institute of } \\
\text { Inorganic Chemistry }\end{array}$ \\
\hline Keywords: & $\begin{array}{l}\text { Host-Guest Systems, Intercalations, Layered compounds, Polymers, } \\
\text { Colloids }\end{array}$ \\
\hline \\
\hline $\begin{array}{l}\text { Note: The following files were submitted by the author for peer review, but cannot be converted } \\
\text { to PDF. You must view these files (e.g. movies) online. }\end{array}$ \\
\hline figure1.cdx \\
\hline
\end{tabular}

\section{S ScholaroNE \\ Manuscript Central}




\title{
ARTICLE
}

\section{Formation of an inorganic-organic host-guest material by intercalation of acetone formaldehyde sulfite polycondensate into a hydrocalumite structure}

\author{
Johann Plank, ${ }^{*[a]}$ Friedrich von Hoessle ${ }^{[a]}$
}

Keywords: Intercalations; Layered compounds; Polymers; Host-Guest Systems; Colloids

\begin{abstract}
An acetone formaldehyde sulfite based polycondensate (Mw 64 $\mathrm{kDa}$ ) which is commonly used as a superplasticizer in cement and concrete, was intercalated into a hydrocalumite type LDH structure. Preparation was done by controlled rehydration of tricalcium aluminate in the presence of the polymer. Formation of the LDH phase was confirmed by XRD, IR and TG measurements. Elemental composition of the organo-mineral phase reveals charge
\end{abstract}

\section{Introduction}

Dispersants such as e.g. polycarboxylates (PCE) and Bnaphthalenesulfonate-formaldehyde based polycondensates (BNS) which are widely used as superplasticizers in concrete have been reported to intercalate into cement hydrates under favorable conditions [1-4]. Upon hydration which is often referred to as rehydration [5], the cement clinker phase tricalcium aluminate $\left(\mathrm{Ca}_{3} \mathrm{Al}_{2} \mathrm{O}_{6}\right.$, abbreviation $\mathrm{C}_{3} \mathrm{~A}$ ) can form layered double hydroxides of the hydrocalumite type. Anionic superplasticizer polymers of various structure and molecular weight can counterbalance the charge of the cationic sheets and intercalate between the layers. In this study, a linear acetone formaldehyde sulfite polycondensate (AFS) [6] has been synthesized and was used in rehydration experiments with tricalcium aluminate. Its chemical structure is presented in Figure 1. Because of the structural similarity of AFS with other polycondensates (e.g. BNS) it seemed possible to obtain novel organomineral phases from the reaction of AFS with $\mathrm{C}_{3} \mathrm{~A}$.

\footnotetext{
Prof. J.Plank,

E-mail: johann.plank@bauchemie.ch.tum.de

[a] Technische Universität München,

Lehrstuhl für Bauchemie,

Lichtenbergstr.4, 85747 Garching, Germany

Fax: +49 (89) 28913152

http://www.bauchemie.ch.tum.de
}

For this purpose, the aluminate phase was reacted with the polymer to form structures of the type $\left[\mathrm{Ca}_{2} \mathrm{Al}(\mathrm{OH})_{6}\right]^{+}[\text {Polymer }]^{-} \cdot \mathrm{yH}_{2} \mathrm{O}$. The reaction product was characterized regarding its structure, composition and morphology. Moreover, typical features of organic polymerLDH compounds usually reported in literature [7-9] have been probed. To be able to compare the properties of the resulting intercalate, the layered model compound $4 \mathrm{CaO}$. $\mathrm{Al}_{2} \mathrm{O}_{3} \cdot \mathrm{xH}_{2} \mathrm{O}$ (abbreviation $\mathrm{C}_{4} \mathrm{AH}_{\mathrm{x}}$ ) which represents the host structure for the AFS guest molecule was also synthesized. It possesses the ideal composition of $\left[\mathrm{Ca}_{2} \mathrm{Al}(\mathrm{OH})_{6}\right]^{+}[\mathrm{OH}]^{-} \cdot \mathrm{y}\left(\mathrm{H}_{2} \mathrm{O}\right)[10]$, with y being in the range

\begin{abstract}
balancing of the cationic LDH main layers by the polycondensate and $\mathrm{OH}^{-}$ions. Low crystallinity observed by XRD and presence of LDH foils was verified by SEM images. There, the novel Ca-Al-LDH phase shows a morphology of intergrown platelets which is typical for layered calcium aluminate hydrates. Depending on the preparation method, ultrathin foils with $20 \mathrm{~nm}-50 \mathrm{~nm}$ thickness were observed. TEM images also support presence of a layered structure.

from 0 to 12 [11]. At room temperature and relative humidity of approximately $30 \%$, the phase $\mathrm{C}_{4} \mathrm{AH}_{13}(\mathrm{x}=13)$ is the stable modification.
\end{abstract}

\section{Results and Discussion}

\section{XRD analysis}

The Ca-Al-AFS-LDH composite was synthesized by reacting $1 \mathrm{~g}$ of tricalcium aluminate with $100 \mathrm{~mL}$ of a 2 wt. $\%$ aqueous AFS solution for 24 hours at room temperature under nitrogen protection to avoid carbonation of the product. The XRD pattern for the Ca-Al-AFS-LDH is shown in Figure 2. At $3.3^{\circ} 2 \theta$ a reflection is observed which can be attributed to the [001] reflections of the layered material. The corresponding $\mathrm{d}$ value which represents the basal spacing in the intercalate is $27 \AA$. One weak harmonic is observed at $d=13.5 \AA\left(6.5^{\circ} 2 \theta\right)$. Further reflections for [hk0] of the host-guest system can be found at approx. $31.5^{\circ}$ $2 \theta$ and for [0k0] at about $55.8^{\circ} 2 \theta$. This XRD pattern confirms the intercalation of AFS into the Ca-Al-LDH host structure and a certain stacking regularity of the tactoid. Similar d values were reported for organic sulfonated compounds such as e.g. poly(vinyl sulfonate) and poly(styrene sulfonate) [12] and alkyl sulfonates [13]. There, basal spacings in the range of $13.2 \AA-19.6 \AA$ and $27.0 \AA-$ $32.3 \AA$, respectively were found. For comparison, the XRD pattern of synthesized $\mathrm{C}_{4} \mathrm{AH}_{13}$ is shown in Figure 2. It exhibits a [001] reflection at $11.2^{\circ} 2 \theta$ which corresponds to a basal spacing of only $7.9 \AA$, compared to $27 \AA$ for the intercalate. Thus it is shown that incorporation of AFS significantly increases the interlayer distance. The steric size of AFS, the elemental composition of the intercalate as shown below and the $\mathrm{d}$ value obtained from XRD suggest that the polycondensate is positioned in a zig zag mode in between the cationic sheets whereby the sulfonated side chains are bound alternatively to the top and bottom layer, and hydroxide anions and water molecules fill the interstitial space. 


\section{IR and ${ }^{27} \mathrm{Al}$ NMR analysis}

In Figure 3, a comparison of the IR spectra of the AFS polymer, the model phase $\mathrm{C}_{4} \mathrm{AH}_{\mathrm{x}}$, and the organo-LDH phase is presented. The IR bands for $\mathrm{C}_{4} \mathrm{AH}_{13}$ have already been described by Henning [14] and Houtepen [15]. Strong absorption occurs at $430 \mathrm{~cm}^{-1}$ and $540 \mathrm{~cm}^{-1}$, due to the vibrational modes of calcium-oxygen and aluminum-oxygen octahedra within the sheets. Other typical absorptive bands of calcium aluminates are overlapping with the polymeric absorption bands in the intercalate. Frequencies for AFS are detected in the range of $1040 \mathrm{~cm}^{-1}$ for the ether linkage and at $1200 \mathrm{~cm}^{-1}$ and $1400 \mathrm{~cm}^{-1}$ for the stretching modes of the sulfonate group. The carbonyl function can be observed at $1700 \mathrm{~cm}^{-1}$ and $\mathrm{CH}_{2}$ stretching at frequencies of $2900 \mathrm{~cm}^{-1}$. The organo-LDH phase shows the frequencies of both individual compounds, $\mathrm{C}_{4} \mathrm{AH}_{\mathrm{x}}$ and AFS. Obviously, both the inorganic host structure and the organic guest molecule are present in the product.

${ }^{27} \mathrm{Al}$ MAS NMR spectroscopy was performed to probe the coordination state of aluminium in the dried hydration product. The spectrum exhibits only one sharp resonance at $\delta=9.2 \mathrm{ppm}$ which signifies octahedral coordination of $\mathrm{Al}$ (see Figure 4). The absence of a broad signal occurring at a lower chemical shift than the resonance from the $\mathrm{Ca}-\mathrm{Al}$ AFS-LDH structure confirms that no $\mathrm{Al}(\mathrm{OH})_{3}$ was formed as a by-product of this reaction.

\section{Elemental analysis}

Incorporation of the AFS polymer into the Ca-Al-LDH frame was confirmed by elemental analysis. A carbon content of $27.9 \mathrm{wt} . \%$ was found for the product (see Table 1). This value significantly exceeds the usual $5 \mathrm{wt} \%$ which is the typical upper limit for surface adsorption of AFS-type polyelectrolytes on LDH crystal surfaces. Additionally, a sulphur content of $6.6 \mathrm{wt} . \%$ was determined for the composite, verifying the chemisorption of AFS into the hydrocalumite host structure. Based on the analytical data, the approximate composition for the Ca-Al-AFS-LDH was calculated and is shown in Table 1. For calculation of the formula, the points as follows were considered: The molar ratio of calcium to aluminum in the intercalate is $2: 1$. Charge compensation between the cationic main sheets and the guest anions is achieved by AFS molecules and $\mathrm{OH}^{-}$ions The formation of $\mathrm{Ca}(\mathrm{OH})_{2}$ and $\mathrm{Al}(\mathrm{OH})_{3}$ as by-products was ruled out because of the results obtained by elemental analysis, XRD and ${ }^{27}$ Al MAS NMR spectroscopy. The value of the organic part can be derived from the calculated formula of the LDH. Additionally, water molecules are present in the interlayer region.

Table 1. Elemental composition and calculated formula of the $\mathrm{Ca}$ Al-AFS-LDH

\begin{tabular}{cccccc}
\hline Sample & \multicolumn{5}{c}{ Elemental composition } \\
& $\mathrm{C}$ & $\mathrm{H}$ & $\mathrm{S}$ & $\mathrm{Ca}$ & $\mathrm{Al}$ \\
& wt.\% & wt.\% & wt.\% & wt.\% & wt.\% \\
\hline $\begin{array}{c}\text { AFS polymer } \\
\text { Ca-Al-AFS } \\
\text { LDH }\end{array}$ & 40.5 & 5.8 & 9.3 & - & - \\
\hline
\end{tabular}

\begin{tabular}{ccc}
\hline & $\begin{array}{c}\text { Organic part } \\
\text { wt.\% }\end{array}$ & Calculated formula \\
\hline AFS polymer & - & $\mathrm{C}_{12} \mathrm{H}_{20} \mathrm{SO}_{8} \mathrm{Na}$ \\
Ca-Al-AFS & $\sim 68.0$ & $\mathrm{Ca}_{2} \mathrm{Al}(\mathrm{OH})_{6} \cdot(\mathrm{AFS})_{1.4}$ \\
LDH & $\left(\mathrm{OH}^{-}\right)_{0,015} \cdot 3.3 \mathrm{H}_{2} \mathrm{O}$ \\
\hline
\end{tabular}

\section{TG analysis}

Thermogravimetric results are shown in Figure 5. The thermal decomposition of the pure $\mathrm{LDH}$ phase $\mathrm{C}_{4} \mathrm{AH}_{\mathrm{x}}$ follows a simple dehydration route as can be seen from Figure 6. Water release occurs at temperatures around $200^{\circ} \mathrm{C}(9$ wt. $\%), 300^{\circ} \mathrm{C}(11$ wt. $\%)$ and above $400^{\circ} \mathrm{C}(5$ wt.\%). The first two conversions stem from dehydration of $\mathrm{C}_{4} \mathrm{AH}_{13}$ to $\mathrm{C}_{4} \mathrm{AH}_{10}$ and $\mathrm{C}_{4} \mathrm{AH}_{7}$ respectively, the latter being the ideal composition of $\left[\mathrm{Ca}_{2} \mathrm{Al}(\mathrm{OH})_{6}\right]^{+}[\mathrm{OH}]^{-}$. Each weight loss is within the range of the theoretical value of approx. 10 wt. \% for each release of water. Beginning from $400^{\circ} \mathrm{C}$, the inorganic framework decomposes because of dehydroxylation. AFS polymer shows release of water at $110^{\circ} \mathrm{C}-150^{\circ} \mathrm{C}$ and in the range of $250^{\circ} \mathrm{C}$ to $380^{\circ} \mathrm{C}$. This second area of temperature stability is moved to slightly higher temperatures in the LDH material and a sharp release of water occurs at $400^{\circ} \mathrm{C}$. The final steep drop in the TG graph of the AFS-LDH can also be ascribed to the release of $\mathrm{SO}_{2}$ (see Figure 7). The sulfonate groups present in free AFS polymer start to decompose $\sim 300^{\circ} \mathrm{C}$ whereas the hybrid material releases $\mathrm{SO}_{2}$ beginning at $\sim 400^{\circ} \mathrm{C}$. Obviously, the LDH framework keeps the polymer from decomposing until the framework itself breaks down. This result confirms that strong interaction between the anionic guest polyelectrolyte and the cationic host sheets occur.

\section{SEM and TEM investigations}

SEM images show platy crystals which are intergrown to form flower-like particles. In some cases, ultra-thin sheets were observed. There, several layers are grouped together to form nanometer scaled structures possessing a thickness of only $20 \mathrm{~nm}-50 \mathrm{~nm}$, as shown in Figure 8 . No evidence for pure $\mathrm{C}_{4} \mathrm{AH}_{\mathrm{x}}$ particles exhibiting the morphology of hexagonal platelets or any other crystalline impurities were found in microscopic investigations. TEM observations indirectly support intercalation and subsequent layer-spacing enlargement (see Figure 9).

\section{Conclusions}

Several investigations have been conducted to probe the intercalation ability of acetone formaldehyde sulfite polycondensate superplasticizers into a hydrocalumite structure. It is demonstrated that AFS can be successfully intercalated into a Ca-Al-LDH structure, resulting in a host-guest compound. These phases of low crystallinity and organic contents of approx. 70 wt.\% show enhanced thermal stability of the AFS polymer. The practical importance of this study is that it offers an explanation for the differences in dispersing effectiveness of AFS at early and delayed addition to concrete. When AFS is present at the start of 
concrete mixing, a portion of it may intercalate into early $\mathrm{C}_{3} \mathrm{~A}$ hydrates and therefore is lost for dispersion effect. Whereas at delayed addition, $\mathrm{C}_{3} \mathrm{~A}$ has already hydrated sufficiently to form $\mathrm{C}_{4} \mathrm{AH}_{\mathrm{x}}$ phases which no longer allow intercalation of AFS. Second, the AFS-LDH could be a useful admixture for concrete, namely for slow release formulations where AFS superplasticizer is gradually exchanged by other anions present in the cement pore solution.

\section{Experimental Section}

The acetone formaldehyde sulfite polycondensate was synthesized according to a description by Plank et al. using a base catalyzed aldol-type reaction [16]. The polymer was dialyzed prior to usage using a SpectraPor dialysis membrane $(\mathrm{MWCO}=6000 \mathrm{Da})$. The molar ratio of acetone, formaldehyde and sulfite was chosen as 1 : $3: 0.5$, the resulting molecular weight $\left(\mathrm{M}_{\mathrm{w}}\right)$ was determined by GPC measurement to be $64 \mathrm{kDa}$ with a polydispersity index of 4.0 . The amount of anionic charge present in the polymer was determined by polyelectrolyte titration in a streaming current charge detector (PCD 03 pH; Mütek Analytic, Herrsching, Germany) to be $2800 \mu \mathrm{eq} / \mathrm{g}$.

Cubic tricalcium aluminate was prepared according to Stephan and Wilhelm [17] using a sol-gel method and subsequent calcination. The resulting product was ground to a particle size $\left(D_{50}\right)$ of $4.0 \mu \mathrm{m}$. Purity of the $\mathrm{C}_{3} \mathrm{~A}$ sample was confirmed via XRD measurement. Pure $\mathrm{C}_{4} \mathrm{AH}_{\mathrm{x}}$ was prepared according to Faucon et al. [18] by reacting $\mathrm{C}_{3} \mathrm{~A}$ with saturated lime solution at low temperature $\left(\sim 5^{\circ} \mathrm{C}\right)$ under exclusion of air to avoid carbonation. The resulting precipitate was centrifuged and after washing with cold water, white crystals were obtained. This powder was dried over saturated $\mathrm{CaCl}_{2}$ solution at room temperature. Preparation of Ca-Al-AFS$\mathrm{LDH}$ was done as follows: Under vigorous stirring $1 \mathrm{~g}$ of $\mathrm{C}_{3} \mathrm{~A}$ was added to $100 \mathrm{~mL}$ of $2 \mathrm{wt}$. $\%$ aqueous AFS solution and reacted at room temperature for 24 hours, again under exclusion of air to avoid carbonation. The product was recovered by centrifugation. The wet precipitate was dried in a desiccator under reduced pressure ( 15 Torr / silica gel).

XRD diffraction patterns were recorded using $\mathrm{Cu} \mathrm{K} \alpha$ radiation on a BRUKER AXS D8 diffractometer. The phases of interest were dried as already described prior to measurement and a slight grinding was applied to the powder products. TG measurements were conducted using a NETZSCH TG 209 system which was equipped with a mass spectrometer for weight loss investigation. IR spectra were taken on a JASCO FT-IR 460 Plus using $\mathrm{KBr}$ pellets. ${ }^{27} \mathrm{Al}$ MAS NMR spectroscopy was performed on a Bruker AV300 NMR spectrometer using a $4 \mathrm{~mm}$ rotor and $15 \mathrm{kHz}$ with 2050 scans $\left(78.2061 \mathrm{MHz}\right.$ for $\left.{ }^{27} \mathrm{Al}\right)$. The elemental composition of the samples was determined using conventional CHNS analysis. Ca and $\mathrm{Al}$ contents were obtained by atomic absorption spectroscopy. SEM pictures were taken on a FEI XL 30 FEG environmental scanning electron microscope. TEM investigation was conducted on a JEOL JEM 2010 microscope.

\section{Acknowledgments}

The authors would like to thank Dr. M. Hanzlik for the TEM images, Dr. G. Raudaschl-Sieber for NMR measurements, Dipl.Chem. M. Gretz for recording of SEM pictures and R. Beiderbeck for TG measurements. The contribution of N. Zou is greatly acknowledged.
[1] V. Fernon, A. Vichot, N. Le Goanvic, P. Colombet, F. Corazza, U. Costa, American Concrete Institute 1997, SP$173,225-248$.

[2] J. Plank, Z. Dai, P. Andres, Mater. Lett. 2006, 6, 3614 - 3617.

[3] J. Plank, H. Keller, P. Andres, Z. Dai, Inorg. Chim. Acta 2006, 359, $4901-4908$.

[4] J. Plank, Z. Dai, N. Zouaoui, J. Phys. Chem. Solids 2007, 69, $1048-1051$.

[5] S. Carlino, Solid State Ionics 1997, 98, 73 - 84.

[6] J. Plank, A. Aignesberger; DE 3344291A1 1985

[7] C. Taviot-Guého, F. Leroux in Struct. Bonding 2006, 119, pp. $121-159$.

[8] F. Leroux, J. Besse, Chem. Mater. 2001, 13, 3507 - 3515.

[9] A. Khan, D. O`Hare, J. Mater. Chem. 2002, 12, 3191 - 3198.

[10] R. Allmann, Chimia 1970, 24, 99 - 108.

[11] W. Dosch, Clays Clay Miner. 1967, 15, 273 - 292.

[12] C.O. Oriakhi, I.V. Farr, M.M. Lerner, J. Mater. Chem. 1996, 6, $103-107$.

[13] M. Meyn, K. Beneke, G. Lagaly, Inorg. Chem. 1990, 29, $5201-5207$.

[14] O. Henning in Infrared Spectra Miner. 1974, pp. 445 -463.

[15] C. Houtepen, H. Stein, Spectrochim. Acta 1976, 32A, 1409 1414.

[16] J. Plank, F. Dugonjic-Bilic, N. Lummer, J. Appl. Polym. Sci. 2009, 111, 2018 - 2024.

[17] D. Stephan, P. Wilhelm, Z. Anorg. Allg. Chem. 2004, 630, $1477-1483$.

[18] P. Faucon, T. Charpentier, D. Bertrandie, A. Nonat, J. Virlet, J. Petit, Inorg. Chem. 1998, 37, 3726 - 3733.

Received: ((will be filled in by the editorial staff)) Published online: ((will be filled in by the editorial staff))

Figure 1. Chemical structure of the acetone formaldehyde sulfite polycondensate

Figure 2. XRD pattern of the Ca-Al-AFS-LDH and $\mathrm{C}_{4} \mathrm{AH}_{13}$

Figure 3. IR spectra of $\mathrm{C}_{4} \mathrm{AH}_{\mathrm{x}}, \mathrm{AFS}$ and the CaAl-AFS-LDH

Figure 4. ${ }^{27} \mathrm{Al}$ MAS NMR spectra of Ca-Al-AFSLDH

Figure 5. TG analysis of $\mathrm{C}_{4} \mathrm{AH}_{\mathrm{x}}$, AFS and the CaAl-AFS-LDH

Figure 6. TG-MS curves of $\mathrm{C}_{4} \mathrm{AH}_{\mathrm{x}}$, AFS and the Ca-Al-AFS-LDH for $\mathrm{m} / \mathrm{z}=18$ (release of $\mathrm{H}_{2} \mathrm{O}$ )

Figure 7. TG-MS curves of $\mathrm{C}_{4} \mathrm{AH}_{\mathrm{x}}$, AFS and the $\mathrm{Ca}-\mathrm{Al}-\mathrm{AFS}-\mathrm{LDH}$ for $\mathrm{m} / \mathrm{z}=64$ (release of $\mathrm{SO}_{2}$ ) 
Figure 8. SEM micrograph of Ca-Al-AFS-LDH (magnification: 20,000)

Figure 9. TEM micrograph of Ca-Al-AFS-LDH 


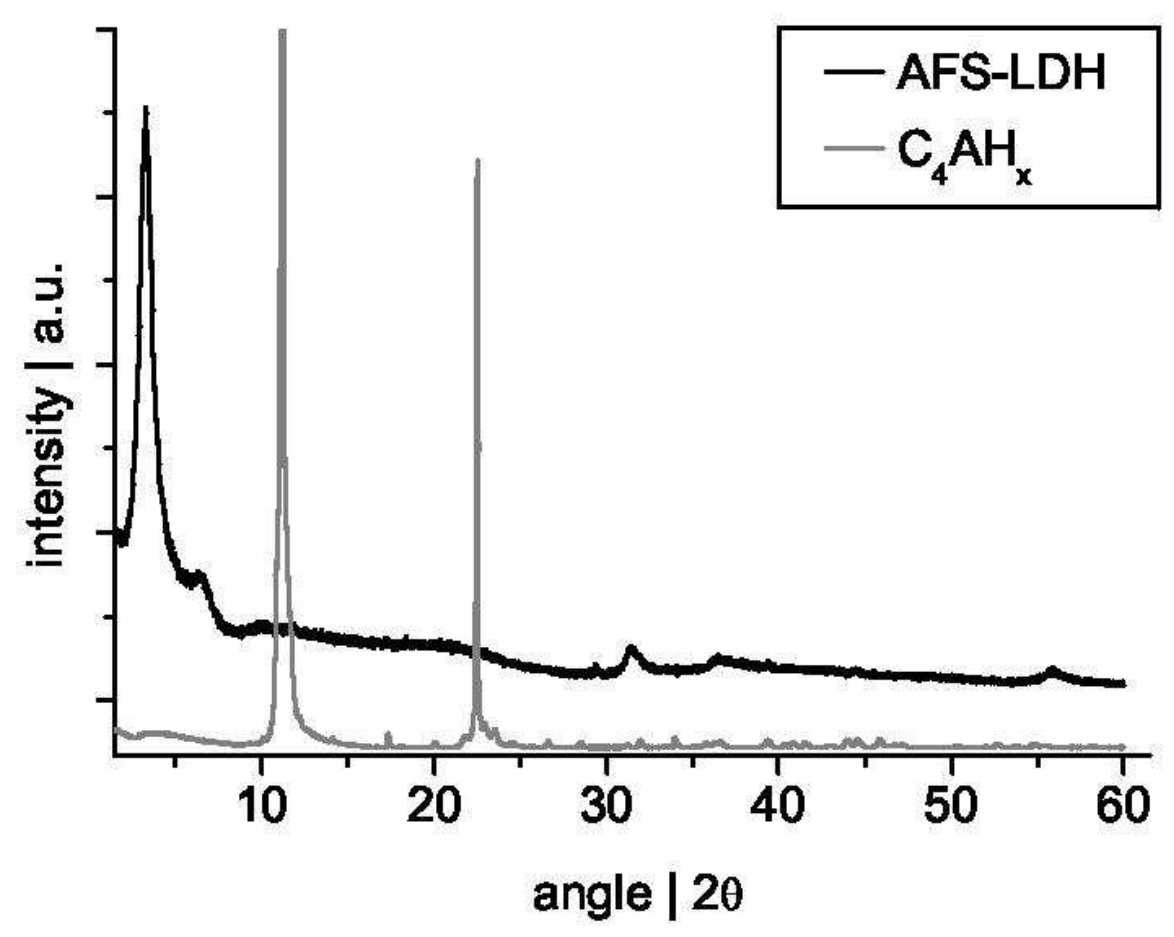

$33 \times 27 \mathrm{~mm}(600 \times 600 \mathrm{DPI})$ 


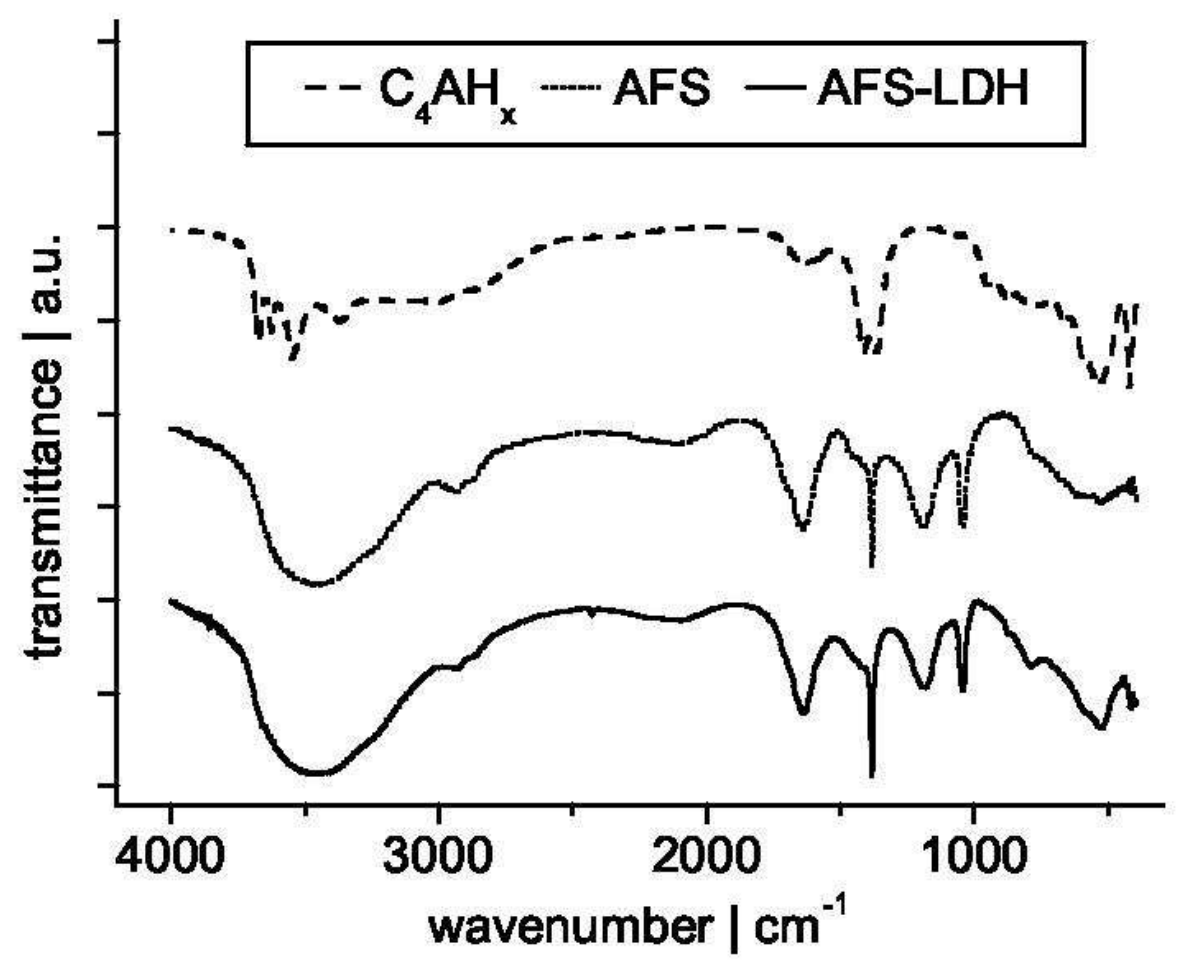

$33 \times 27 \mathrm{~mm}(600 \times 600 \mathrm{DPI})$ 


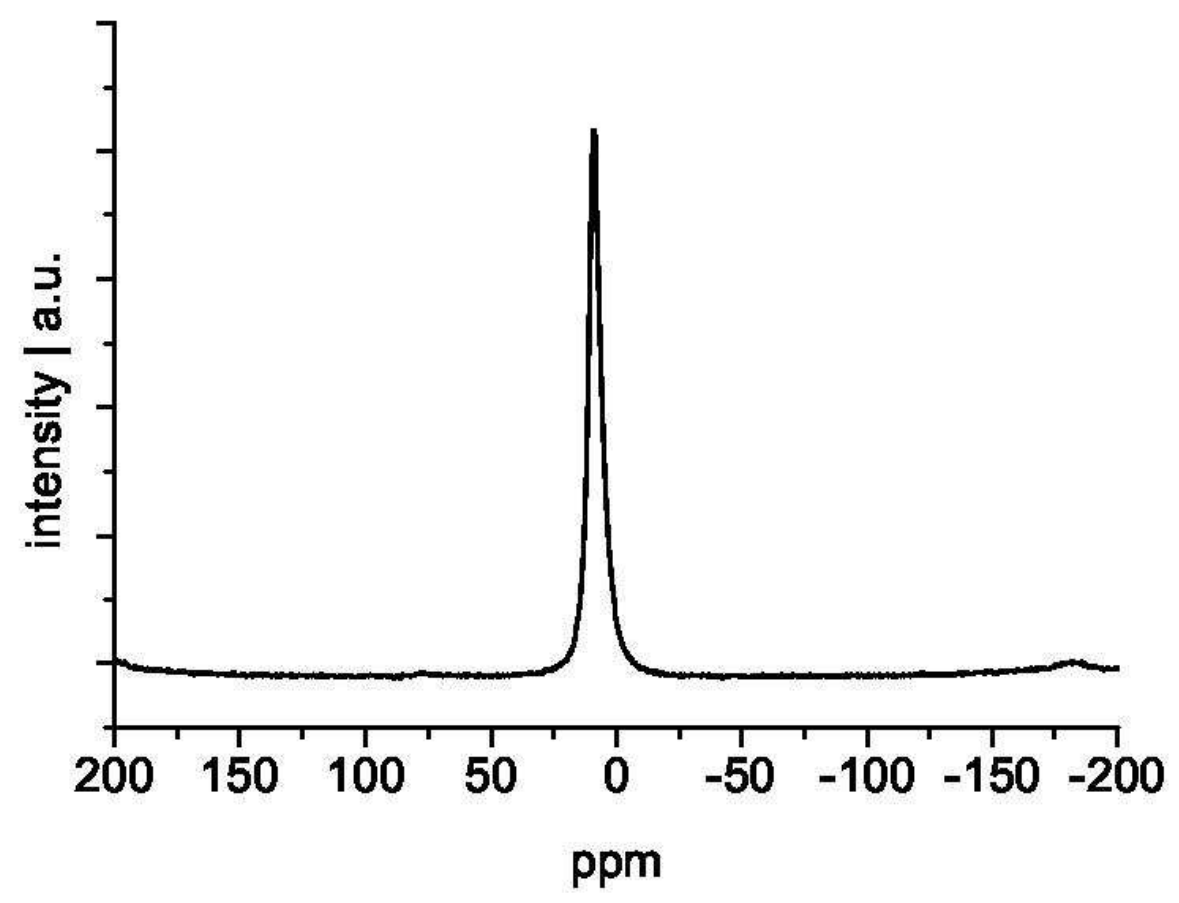

$34 \times 27 \mathrm{~mm}(600 \times 600 \mathrm{DPI})$ 


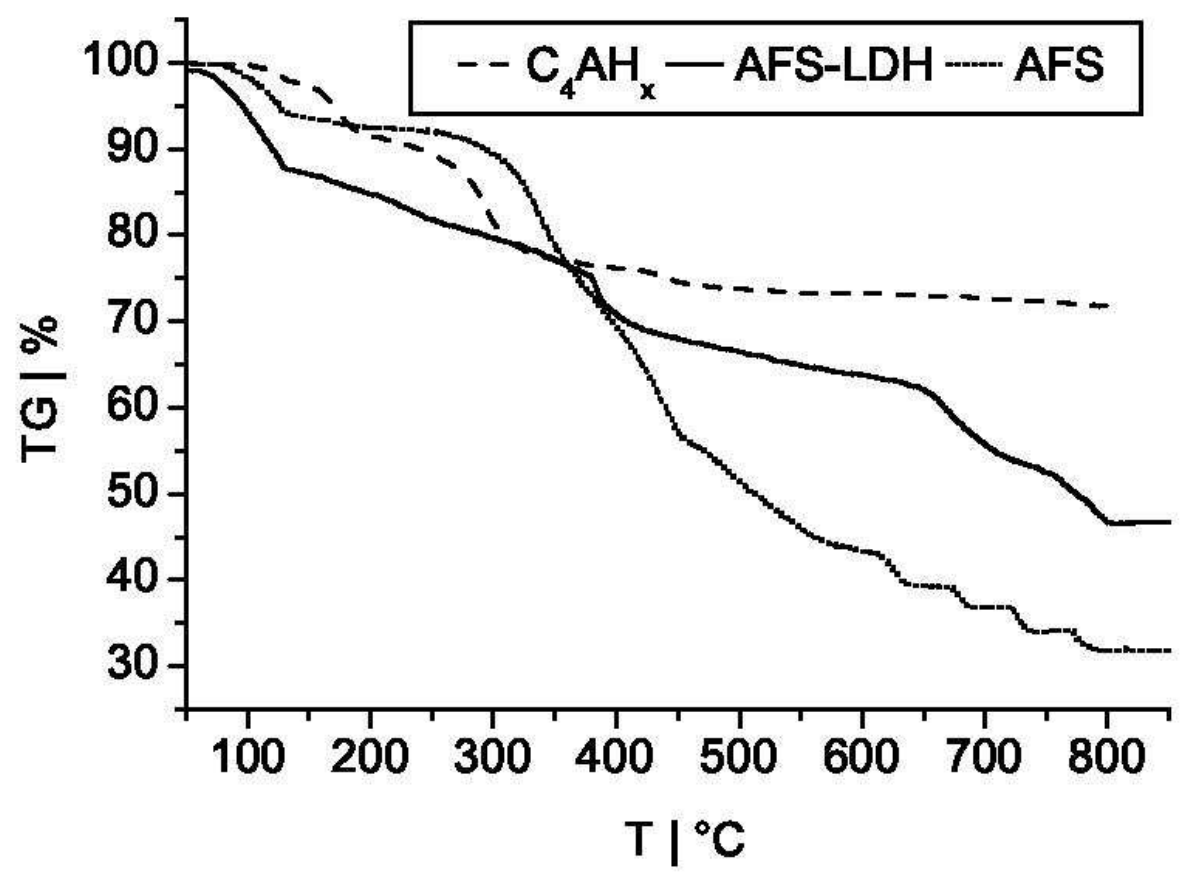

$35 \times 27 \mathrm{~mm}(600 \times 600$ DPI $)$ 


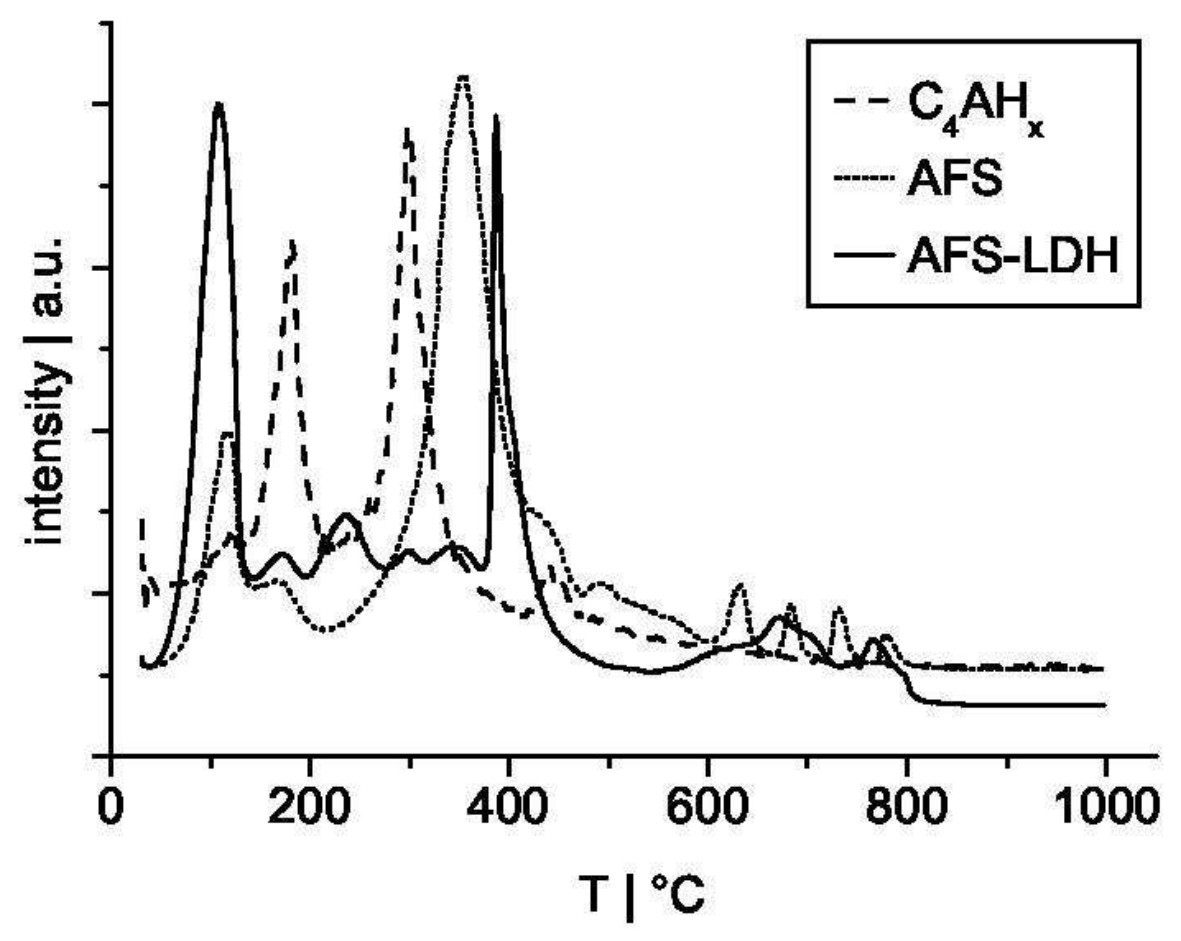

$33 \times 27 \mathrm{~mm}(600 \times 600$ DPI $)$ 


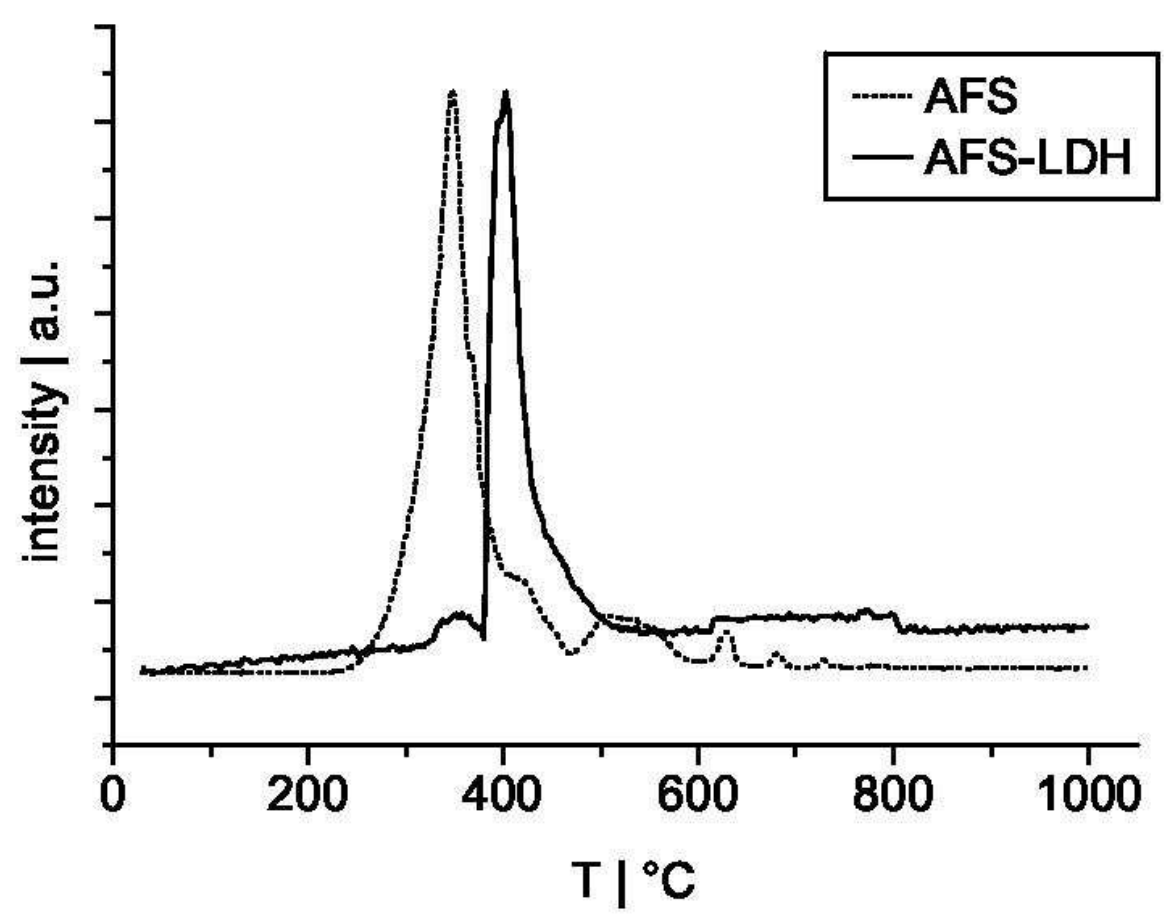

$34 \times 27 m m(600 \times 600$ DPI $)$ 


\section{Page 11 of 12}

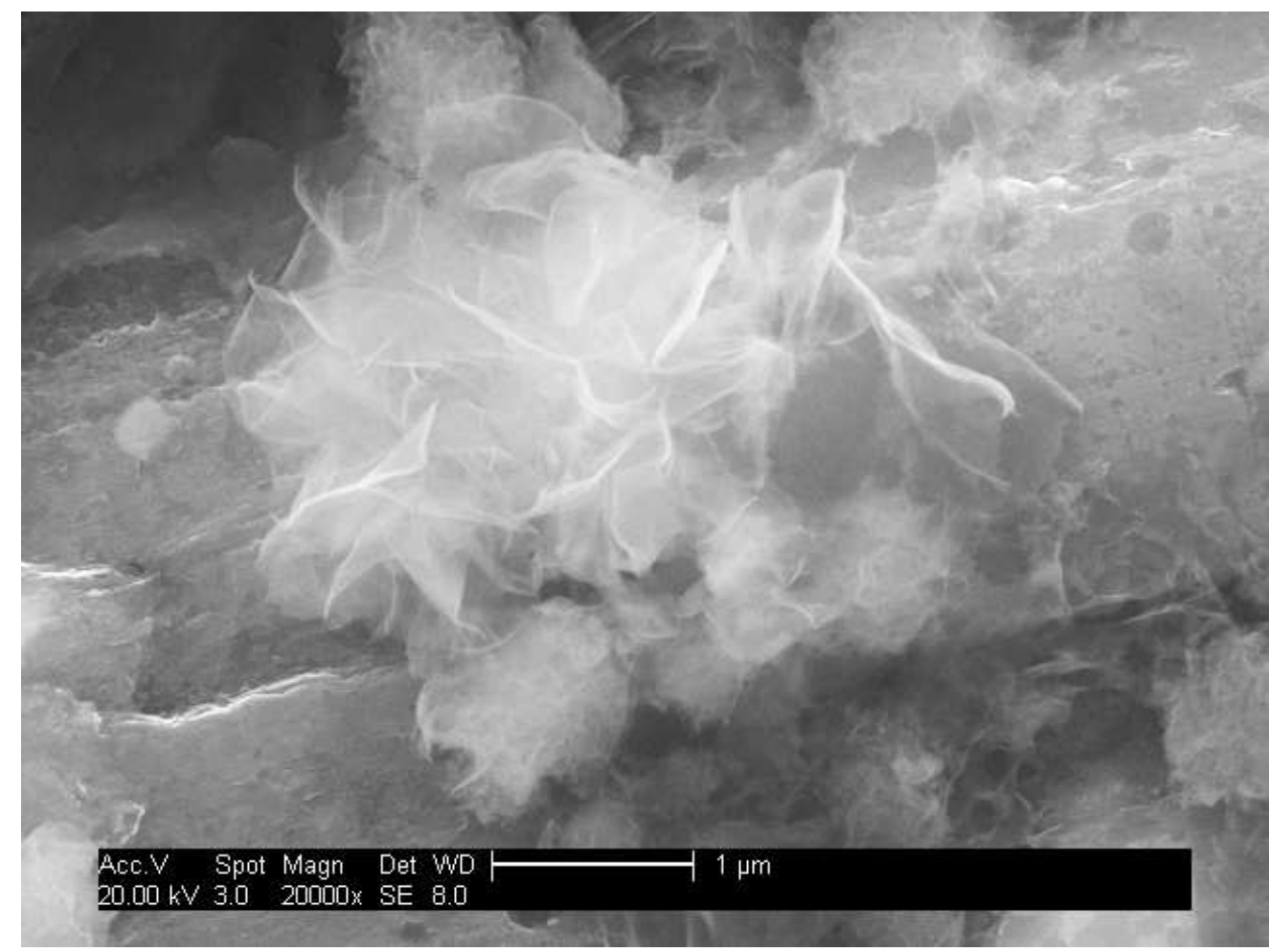

$227 \times 170 \mathrm{~mm}(72 \times 72 \mathrm{DPI})$ 


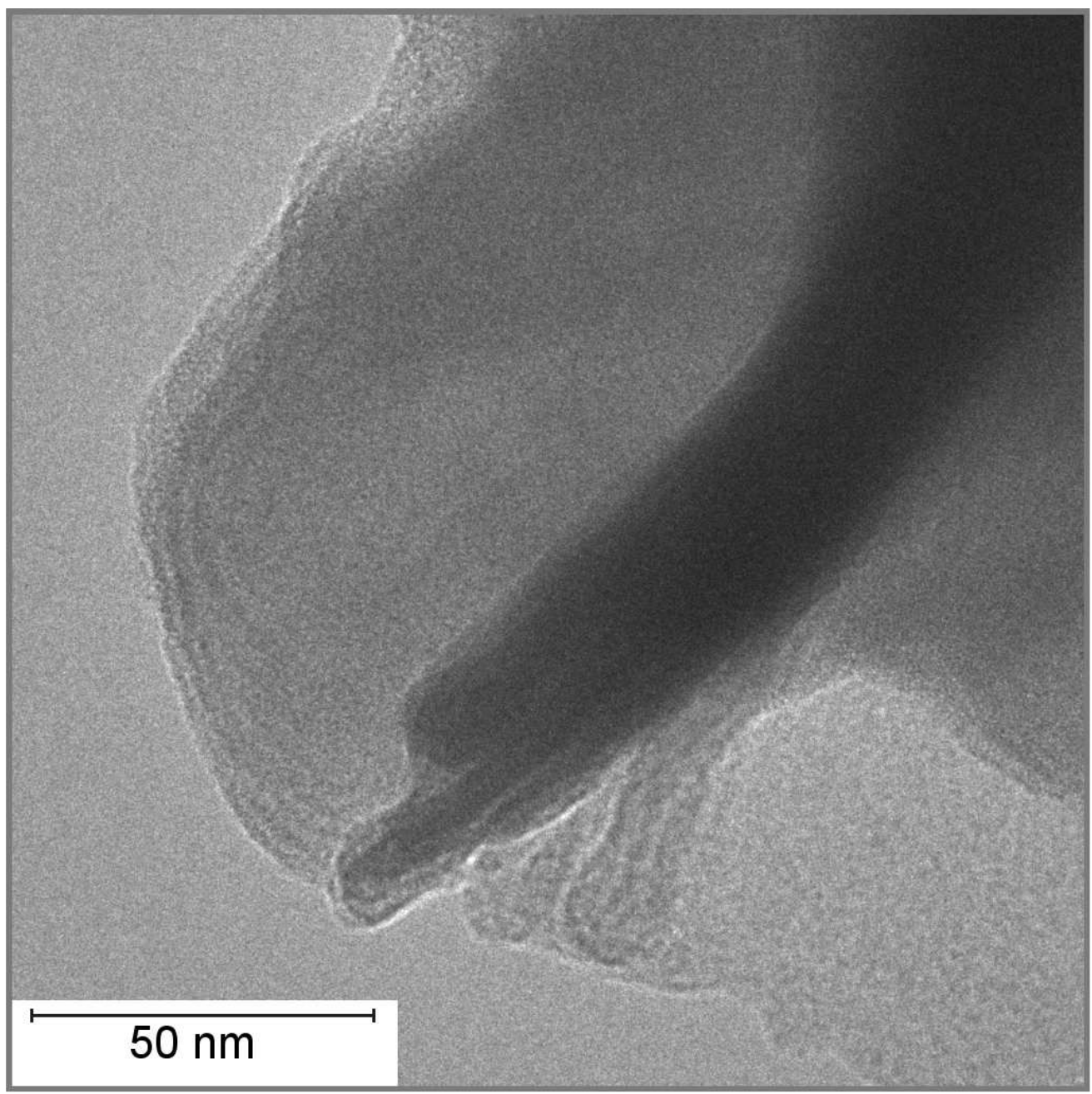

